\title{
Numerical Modeling of Gas Migration and Hydrate Formation in Heterogeneous Marine Sediments
}

\author{
Keqi Bei, Tianfu Xu, Songhua Shang, Zilin Wei, Yilong Yuan and Hailong Tian * \\ Key Laboratory of Groundwater Resources and Environment, Ministry of Education, Jilin University, \\ Changchun 130021, China; beikeqi001@163.com (K.B.); tianfu_xu@jlu.edu.cn (T.X.); \\ shangsh1995@foxmail.com (S.S.); zilin_wei@163.com (Z.W.); yuan_yilong@126.com (Y.Y.) \\ * Correspondence: myname1978@163.com
}

Received: 26 August 2019; Accepted: 27 September 2019; Published: 2 October 2019

\begin{abstract}
The formation of marine gas hydrates is controlled by gas migration and accumulation from lower sediments and by the conditions of the hydrate stability zone. Permeability and porosity are important factors to evaluate the gas migration capacity and reservoir sealing capacity, and to determine the distribution of hydrates in the stable region. Based on currently available geological data from field measurements in the Shenhu area of Baiyun Sag in the northern South China Sea, numerical simulations were conducted to estimate the influence of heterogeneities in porosity and permeability on the processes of hydrate formation and accumulation. The simulation results show that: (1) The heterogeneity of the hydrate stability zone will affect the methane migration within it and influence the formation and accumulation of hydrates. This is one of the reasons for the formation of heterogeneous hydrates. (2) When the reservoir is layered heterogeneously, stratified differences in gas lateral migration and hydrate formation will occur in the sediment, and the horizontal distribution range of the hydrate in a high porosity and permeability reservoir is wider. (3) To determine the dominant enrichment area of hydrate in a reservoir, we should consider both vertical and lateral conditions of the sedimentary layer, and the spatial coupling configuration relationships among the hydrate stability region, reservoir space and gas migration and drainage conditions should be considered comprehensively. The results are helpful to further understand the rules of hydrate accumulation in the Shenhu area on the northern slope of the South China Sea, and provide some references for future hydrate exploration and the estimation of reserves.
\end{abstract}

Keywords: natural gas hydrate; formation and accumulation; numerical simulation; heterogeneity; northern South China Sea; Shenhu area

\section{Introduction}

Natural gas hydrate is an ice-like crystalline mineral, in which hydrocarbon and non-hydrocarbon gases are held within rigid cages of water molecules [1]. Since their discovery in marine sediments by the International Deep Sea Drilling Programme (DSDP) in 1979, natural gas hydrates are receiving increasing attention around the word [2]. Since 1999, natural gas hydrate surveys on the northern slope of the South China Sea (SCS) have been carried out in China. Geological evidence (such as pock marks, mud volcanos and cold seeps), geophysical evidence (such as bottom simulating reflectors, BSRs) and geochemical evidence (such as abnormal chlorine concentrations and changes of oxygen isotope) for the existence of natural gas hy drate have been found in the marine sediments (usually at the depth of 300-3000 m) of the Xisha Trough Basin, Qiongdongnan Basin, Pearl River Mouth Basin and Tainan Basin [3-5]. The processes of the formation and accumulation of marine gas hydrates are very complex, and there are four important key factors: stable conditions of temperature and pressure, gas source supply, migration conduction system and a reservoir for gas hydrate formation and accumulation [6]. 
At present, scholars have carried out a lot of research on the formation conditions of hydrates in sea areas, some of which focuses on the analysis of the controlling factors of hydrate formation at the micro-scale [7-10], and other research on the macroscopic geological conditions, such as the influence of tectonic activities, sedimentary environment, reservoir temperature and pressure conditions on the saturation, burial depth and distribution of hydrate reservoirs [11,12]. In some studies, geological and geophysical data have been used to analyze reservoir-forming models and study the evolution of reservoir-forming processes $[13,14]$. Drilling results show that the gas hydrate reservoirs in the Shenhu area are dominated by fine grained clayey silt sediments, and the reservoirs have higher porosity and permeability in local parts [4]. At the same time, there are great differences in the saturation, burial depth and reservoir thickness of hydrates in both lateral and vertical directions, which shows obviously heterogeneous characteristics $[15,16]$. Some studies found that the formation and accumulation of gas hydrates in the Shenhu area may be controlled by the sediment grain $[17,18]$. The heterogeneous characteristics of sediments may be one of the factors affecting the different occurrences of hydrates. However, there are few simulation studies on hydrate formation in heterogeneous sediments. Malinverno [19] studied natural gas hydrate systems and incorporated heterogeneity into a 1-D model by including thin, horizontal sand layers bound by lower permeability clay layers. Chatterjee et al. [20] extended the 1-D model into two dimensions and quantitatively studied how focused fluid flow through high permeability zones affects local hydrate accumulation and saturation. Nole et al. [21] studied methane migration in different coarse-grained hydrate reservoirs using 2-D basin-scale simulations.

In this paper, with the aim to evaluate the effects of heterogeneities in permeability and porosity on gas hydrate formation and accumulation, and to fully address gas hydrate distribution in heterogeneous sediments, three-dimensional numerical simulations are conducted based on data from the Shenhu sea area in the northern South China Sea. Compared with the previous two-dimensional model, the three-dimensional model can better reflect the actual stratigraphic situation and better analyze the influence of lateral heterogeneity of strata at the same depth on hydrate formation. Three scenarios (homogeneity, layered heterogeneity and spatial heterogeneity) are considered in this study. After comparison of different modeling results, conclusions are drawn accordingly.

\section{Geologic Setting}

The Shenhu area belongs to the Baiyun Sag of the Zhuer Depression in the Pearl River Mouth Basin, located in the middle of the continental slope, northern South China Sea. The current seabed topography in the Shenhu area is relatively flat (with an average slope gradient of about 3 degrees), and the general trend is higher in the north and lower in the south. The water depth is $1000-1700 \mathrm{~m}$, and the Cenozoic sediment thickness is up to 1000-7000 $\mathrm{m}[22,23]$. The Shenhu area is between the Xisha Trough and Dongsha Islands, and has been in the process of tectonic subsidence since the middle Miocene. In the north of the Shenhu area, where the Quaternary sedimentation rate is high, many slump sediments and debris flows have developed and there is a depression basement topography; in the southeast of the Shenhu area, the Quaternary sedimentation rate is relatively low and an uplift basement topography exists [24].

The seafloor temperatures of the Shenhu area are about $3.3-3.7^{\circ} \mathrm{C}$ with the geothermal gradient in the range of $45-67.7^{\circ} \mathrm{C} / \mathrm{km}$, and the heat flow values are available and range from $60 \mathrm{~mW} / \mathrm{m}^{2}$ to $100 \mathrm{~mW} / \mathrm{m}^{2}$. According to the hydrostatic pressure gradient and water depth, the seafloor water pressure in the area is more than $10 \mathrm{MPa}$, which meets the favorable temperature and pressure conditions for hydrate reservoir formation [25]. There are abundant gas sources in Baiyun Sag. The Paleogene Eocene Wenchang Formation and Oligocene Enping Formation have developed mature and mature-high source rocks, producing abundant thermogenic gas. The organic matter maturity of the Zhujiang Formation and Hanjiang Formation is relatively low, so they can serve as biogenic gas source rocks. Combined with biogenic gas in situ in shallow sediments, there are abundant gas sources in the study area for hydrate formation [26]. The Cenozoic multi-stage tectonic movement resulted in 
the development of faults, gas chimneys, slumping and diapir structures in the Shenhu area, which serve as migration pathways for gas and gas-bearing fluids. The typical hydrate reservoir types in the Shenhu area are deep-water turbidite fan, canyon channel and slump deposits. In fine sediments dominated by silt or clayey silt, calcareous microfossils and foraminifers are abundant, which increase the secondary porosities of clayey silt sediments and provide space for gas hydrate formation and accumulation $[27,28]$. From the above, we can find that the Shenhu area is a good prospective area for hydrate reservoirs, and it is also a key area for gas hydrate exploration in China's sea area.

In 2007 and 2015, the Guangzhou Marine Geological Survey organized two voyages of hydrate drilling (GMGS1 and GMGS3) in this area, and obtained hydrate samples. Drilling results show that both the depth of the drilling area and the conditions of pressure and temperature are suitable for hydrate formation, and remain basically the same. However, there are differences in the sources of hydrate gas, reservoir sediments and hydrate types revealed by the two drilling results, and the saturation and thickness of hydrate show obvious heterogeneity in space [14,29]. Yang et al. [16] produced statistics on the effective thickness and average saturation of hydrates in existing wells in the Shenhu area. It was found that the thickness, saturation, and distribution depth of gas hydrate reservoirs in the Shenhu area are different in different depths of a single borehole or different wells, i.e., the gas hydrate has distinct heterogeneity [30].

\section{Numerical Modeling}

\subsection{Numerical Simulator}

In this study, the TOUGH + HYDRATE simulator was used to investigate the migration of methane gas and methane-containing fluids and the formation and accumulation of methane hydrates. The code was developed by Lawrence Berkeley National Laboratory to simulate natural gas hydrate based on the TOUGH framework. By solving the coupled equations of mass and heat balance, TOUGH + HYDRATE can model the non-isothermal gas release, phase behavior and flow of fluids and heat under conditions typical of common natural $\mathrm{CH}_{4}$-hydrate deposits in complex geological media in which Darcy's law is valid. The model can simulate the transport of four components (water, $\mathrm{CH}_{4}$, hydrate, and water-soluble inhibitors such as salts or alcohols) between four phases (gas phase, liquid phase, ice phase and hydrate phase). The dissolution and release of methane in water, due to the variation of pressure and temperature, are calibrated on the basis of the fugacity model. This code can model the nonisothermal hydration reaction, multiphase behavior, and flow of fluids and heat under conditions in geological media containing gas hydrates [31,32] patial discretization is implemented by an integral finite different approach, and the time discretization is implicit. The numerical model is solved by Newton-Raphson iteration. Time steps are automatically adjusted depending on the convergence rate [33].

\subsection{Model Set-Up}

\subsubsection{Concept Model and Boundary Conditions}

To explore the process of gas hydrate formation and accumulation under different porosity and permeability conditions, a basic model of known reservoir-cap stratification was established first. In this paper, site W19 in the GMGS3 drilling area is selected as the background study area, and the basic model is established according to the known geological and geophysical data of site W19. The water depth of the W19 station is $1273.9 \mathrm{~m}$, and logging interpretation indicated that there is a hydrate layer with an effective thickness of about $35 \mathrm{~m}$ below $138 \mathrm{mbsf}$ (meters below the seafloor), there is free gas beneath the hydrate layer, and the thickness of the whole resistivity anomaly is about 53.5 $\mathrm{m}[29,34]$. Based on the data, a 3D conceptual model is established, as shown in Figure 1. The model extends $1000 \mathrm{~m}$ horizontally in $\mathrm{X}$ and $\mathrm{Y}$ directions to avoid the boundary effects. The total thickness of the entire model is $500 \mathrm{~m}$, with the thickness of the hydrate reservoir being $53.5 \mathrm{~m}$, and the thickness of 
the overburden and underburden layers being $138 \mathrm{~m}$ and $308.5 \mathrm{~m}$, respectively. According to the trial modeling, the maximum lateral distance of $\mathrm{CH}_{4}$ will not exceed $450 \mathrm{~m}$ in the simulation years, and it is less than the range of simulation. Therefore, for the studied formation, the lateral boundary was set to a Dirichlet boundary (constant pressure and temperature). The top boundary of the model is set as the seawater layer with constant temperature and pressure, and the bottom is a pure methane layer with constant pressure of $16.0 \mathrm{MPa}$ as the gas source layer, which simplifies the complex gas source at the bottom. In the model, the gas leaks upward through a passage of $100 \mathrm{~m} \times 100 \mathrm{~m}$ in the middle of the bottom layer, similar to the gas chimney structure formed by the leakage of overpressure gas. The methane flux used in this study was an average value $\left(2.7 \times 10^{-6} \mathrm{~kg} \cdot \mathrm{m}^{-2} \mathrm{~s}^{-1}\right)$ calculated by constant pressure injection simulations. The process we simulated is similar to a short-range, overpressure-driven methane migration from a certain submarine gas reservoir, where a short-duration methane leakage happened due to a certain geological event.

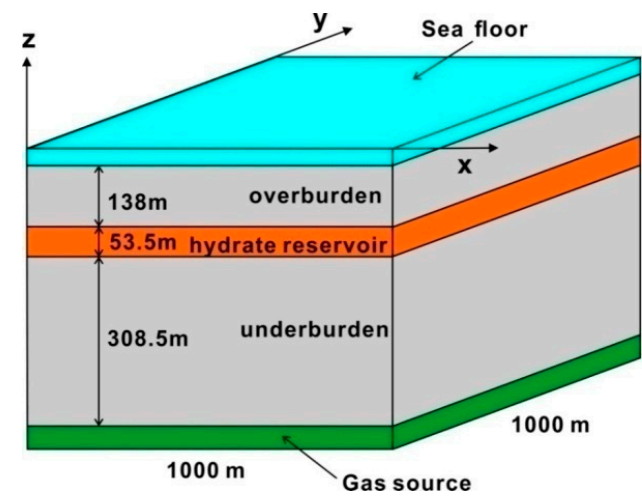

(a) $3 \mathrm{D}$ view

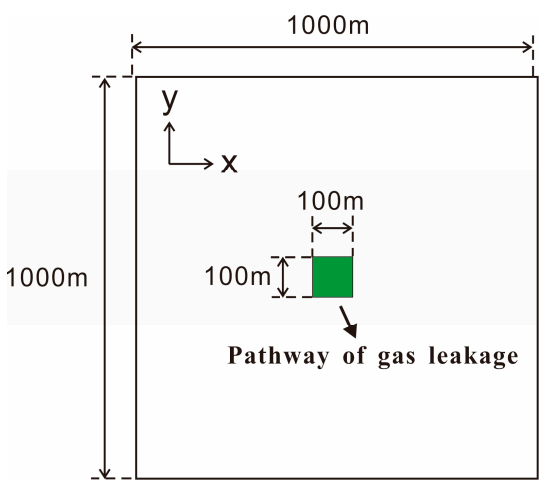

(b) $x-y$ view (bottom layer)

Figure 1. The geometry of the simulation domain.

The model is divided into 20 grids in the $X$ and $Y$ directions, respectively. The overburden and underburden layers in the $\mathrm{Z}$ direction are divided evenly, and the hydrate reservoir is simulated in high resolution. Consequently, the model is divided into 68 layers in the $\mathrm{Z}$ direction, and the number of total grids is $20 \times 20 \times 68=27200$.

\subsubsection{Parameter Setting}

The hydrate is assumed to be only composed of methane migrated from the bottom. Logging data of site W19 show that the pressure and temperature at the bottom of the sea are $12.86 \mathrm{MPa}$ and $3.75{ }^{\circ} \mathrm{C}$, respectively, and the average geothermal gradient is $0.045^{\circ} \mathrm{C} / \mathrm{m}$ [35]. The porosity of the hydrate reservoir is 0.483 , the permeability is $5.5 \mathrm{mD}$, the average porosity of other deposits is 0.424 , and the average permeability is $1.16 \mathrm{mD}$ [34]. The permeability of overburden acting as a caprock of gas in the model is lower than the average value by two orders of magnitude. The porosity and permeability of other formations are set to the measured average values of the formations without hydrates.

The relative permeabilities of liquid and gas vary with the liquid and gas saturation, respectively, which can be inferred from [36]:

$$
\begin{array}{ll}
K_{r A}=\left(S_{A}^{*}\right)^{n_{A}}, \quad S_{A}^{*}=\left(S_{A}-S_{i r A}\right) /\left(1-S_{i r A}\right) \\
K_{r G}=\left(S_{G}^{*}\right)^{n_{G}}, \quad S_{G}^{*}=\left(S_{G}-S_{i r G}\right) /\left(1-S_{i r G}\right)
\end{array}
$$

where $K_{r A}$ and $K_{r G}$ are the relative permeabilities of the aqueous phase and gas phase, respectively, $S_{A}$ is the aqueous saturation, $S_{i r A}$ is irreducible aqueous saturation, $n_{A}$ is the index for the aqueous phase, $S_{i r G}$ is irreducible gas saturation, and $n_{G}$ is the index for the gas phase. 
The capillary pressure in the model is a function of saturation, which can be inferred from [37]:

$$
P_{\text {cap }}=-P_{0}\left(\left[S_{A}^{*}\right]^{-1 / m}-1\right)^{1-m}
$$

where $P_{\text {cap }}$ is the capillary pressure, $\mathrm{m}$ is the index for the pore structure, and $P_{0}$ is the entry capillary pressure.

The composite thermal conductivity in the model is a function of saturation, which can be inferred from [38]:

$$
\lambda=\lambda_{D}+\left(S_{A}^{1 / 2}+S_{H}^{1 / 2}\right)\left(\lambda_{W}-\lambda_{D}\right)
$$

where $\lambda$ is composite thermal conductivity in the hydrate bearing system, and $\lambda_{D}$ and $\lambda_{W}$ are the dry and Wet thermal conductivity, respectively.

The permeability in this study will reduce due to the presence of hydrate, which can be inferred by [39]:

$$
k_{e f f} / k_{0}=\left(\phi_{0}\left(1-S_{H}\right)-\phi_{c} / \phi_{0}-\phi_{c}\right)^{n}
$$

where $k_{e f f}$ is the effective permeability, $k_{0}$ is the intrinsic permeability without hydrate, $\phi_{0}$ is porosity without hydrate, $\phi_{c}$ is the critical mobile phase saturation (i.e., gas and water) corresponding to $k_{e f f}$ of zero, $\mathrm{n}$ is the permeability reduction exponent for solid hydrate, and $S_{H}$ is the hydrate saturation.

The values of related parameters used in the model are summarized in Table 1.

Table 1. Main model parameters of site W19 in the Shenhu area of the SCS.

\begin{tabular}{ccc}
\hline Parameter & Value & Source \\
\hline Upper boundary temperature & $3.75{ }^{\circ} \mathrm{C}$ & {$[35]$} \\
Upper boundary pressure & $12.86 \mathrm{MPa}$ & {$[35]$} \\
Temperature gradient & $0.045{ }^{\circ} \mathrm{C} / \mathrm{m}$ & {$[35]$} \\
Rock grain density & $2600 \mathrm{~kg} / \mathrm{m}^{3}$ & {$[40]$} \\
Rock grain specific heat & $1.0 \mathrm{KJ} /(\mathrm{kg} \cdot \mathrm{K})$ & {$[33]$} \\
Water salinity & $3.05 \%$ & {$[34]$} \\
Hydrate density & $920.0 \mathrm{~kg} / \mathrm{m}^{3}$ & {$[33]$} \\
Hydrate specific heat & $2.1 \mathrm{KJ} /(\mathrm{kg} \cdot \mathrm{K})$ & {$[33]$} \\
Pore compressibility & $1.0 \times 10^{-9} \mathrm{~Pa}-1$ & {$[40]$} \\
Dry thermal conductivity $\left(\lambda_{D}\right)$ & $1.00 \mathrm{~W} /(\mathrm{m} \cdot \mathrm{K})$ & {$[41]$} \\
Wet thermal conductivity $\left(\lambda_{w}\right)$ & $3.10 \mathrm{~W} /(\mathrm{m} \cdot \mathrm{K})$ & {$[41]$} \\
Intrinsic permeability $\left(k_{0}\right)$ & 0.424 & {$[34]$} \\
Porosity $\left(\phi_{0}\right)$ & 0.30 & {$[34]$} \\
Irreducible aqueous saturation $\left(S_{i r A}\right)$ & 5.0 & {$[40]$} \\
Index for the aqueous phase $\left(n_{A}\right)$ & 0.03 & {$[40]$} \\
Irreducible gas saturation $\left(S_{i r}\right)$ & 3.5 & {$[40]$} \\
Index for the gas phase $\left(n_{G}\right)$ & $1.0 \times 10^{5} \mathrm{~Pa}$ & {$[40]$} \\
The entry capillary pressure $\left(P_{0}\right)$ & 0.45 & {$[40]$} \\
Index for the pore structure $(\mathrm{m})$ & 0.05 & {$[33]$} \\
Critical mobile phase saturation $\left(\phi_{c}\right)$ & 3.0 & {$[33]$} \\
Permeability reduction exponent $(\mathrm{n})$ & &
\end{tabular}

\subsubsection{Simulation Scenarios}

The results of drilling in the Shenhu sea area showed that there are certain heterogeneities in the occurrence of hydrates, which is inferred to be related to the heterogeneity in the reservoir. The heterogeneity of sediment is reflected in many parameters, and the two parameters that directly affect fluid migration and heat transfer are permeability and porosity [42]. In this study, we used Hetero- $3 \mathrm{~d}$ to assign random heterogeneous values to the selected areas in the basic model. The principle is to assume that the reservoir permeability follows a lognormal distribution while the porosity varies with permeability [43]. The spatial distribution pattern of permeability is controlled by a variation 
function, and then the specific permeability and porosity in each grid are controlled by a probability density function [44].

In order to explore the influence of the heterogeneity of porosity and permeability on the accumulation of hydrates, three scenarios are designed, as shown in Table 2. A homogeneous basic model (Base-case) is designed to clarify the evolution law of hydrate burial depth and saturation in ideal homogeneous sediments. The layered heterogeneity of sediments (case 1) is to explore the influence of reservoir conditions with layered differential distribution on hydrate formation, and the reservoirs are designed as alternating interbedding structures of low permeability and high permeability layers. The design of the spatial heterogeneity of sediments (case 2) is to explore the influence of reservoir conditions with spatially differential distribution on hydrate formation and accumulation.

Table 2. The designed simulation scenarios.

\begin{tabular}{|c|c|c|}
\hline Case Name & Conditions of the Hydrate Reservoir & Intrinsic Permeability/m ${ }^{2}$ \\
\hline Base-case & homogeneity & $1.16 \times 10^{-15}$ \\
\hline Case 1 & layered heterogeneity & $\begin{array}{l}\text { high permeability layer: } 1.16 \times 10^{-14} \\
\text { low permeability layer: } 1.16 \times 10^{-16}\end{array}$ \\
\hline Case 2 & spatial heterogeneity & $1.16 \times 10^{-13}-1.16 \times 10^{-17}$ \\
\hline
\end{tabular}

\section{Simulation Results}

\subsection{Homogeneous Base Model}

In ideal homogeneous sediments, gas migrates upward without high-speed channels or barriers. In the process of constant pressure injection, gas migrates upward to the hydrate stable zone, and gradually forms hydrate in the stable zone. Figure 2 shows the distribution of methane gas (free gas) and hydrate at different simulation times. It can be found that methane gas migrates upward from the bottom gas source. In the initial stage, the free gas mainly migrates vertically with less lateral diffusion, and reaches the hydrate stability zone at about 300 years, forming a vertically distributed gas chimney on the path of gas, and low saturation $(<0.1)$ hydrate is formed at the bottom of the hydrate stability zone. At the simulation time of 600 years, due to the plugging effect of overlying low permeability sediments and hydrate formation, the vertical flow velocity slows down, the lateral gas migration increases, and a horizontal hydrate layer is formed. The formation of hydrate in the pore reduces the effective permeability of the medium, which improves the gas storage capacity of overlying low permeability sediments and makes gas vertical migration more and more difficult with the continuous supply of methane from the bottom. Methane gas migrates mainly in the lateral direction when it moves near the stable zone. The distribution of hydrate is consistent with the direction of gas migration, the horizontal extension range is expanded, and the thickness of the hydrate layer increases accordingly.

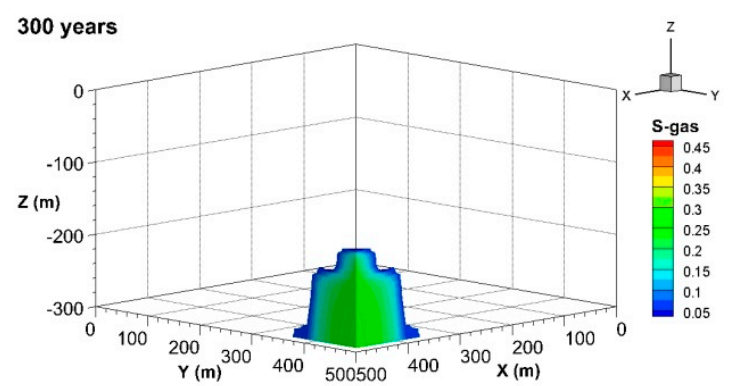

(a) Gas saturation

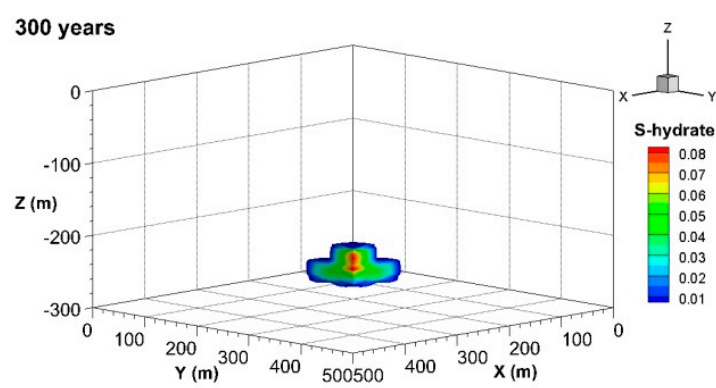

(b) Hydrate saturation

Figure 2. Cont. 


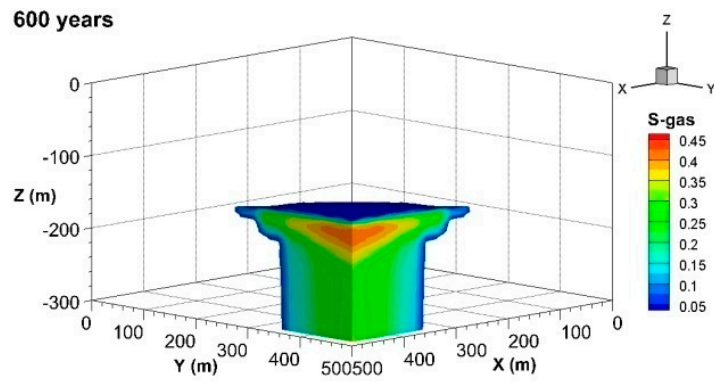

(c) Gas saturation

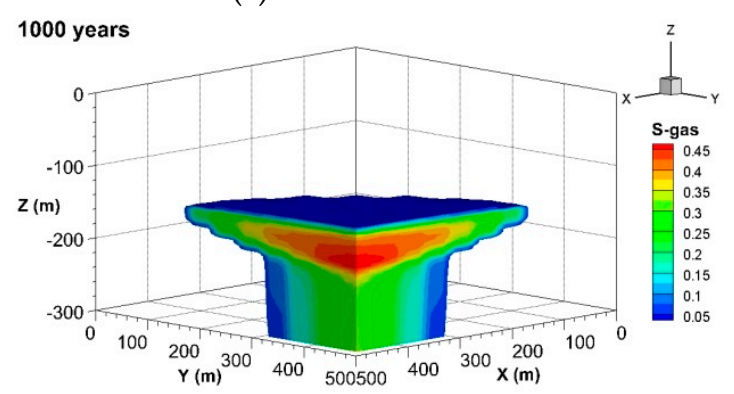

(e) Gas saturation

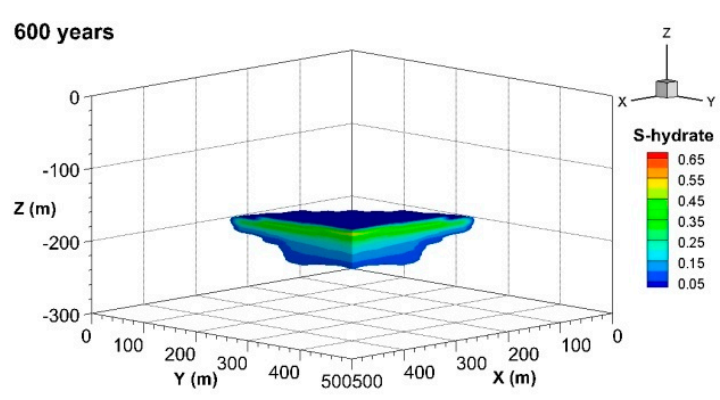

(d) Hydrate saturation

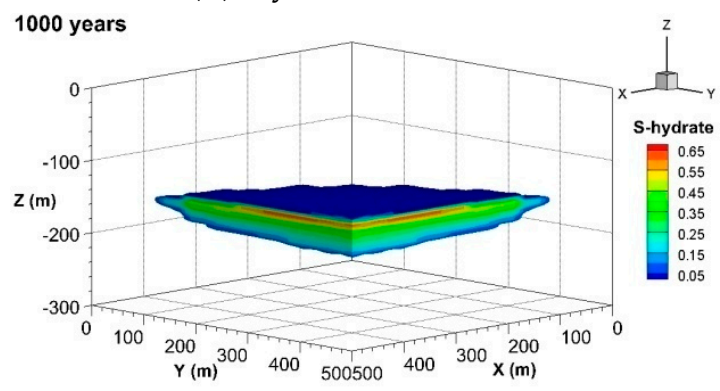

(f) Hydrate saturation

Figure 2. Gas and hydrate distribution at different simulated times (Base-case).

\subsection{Layered Heterogeneity of the Reservoir}

Due to the absence of sufficient substantial geological structure and field test data, most previous numerical studies assumed the hydrate reservoirs to be homogeneous with a single layer. In fact, the drilling of marine gas hydrates in the Eastern Nankai Trough of Japan and in the Shenhu area in the South China Sea has revealed the layered differential distribution of hydrate deposits, which are composed of sand and clay alternating layers with different permeability and porosity $[17,45]$. There are few specific data on porosity and permeability conditions of shallow sediments in the South China Sea. In case 1 , the hydrate reservoir was assumed to have layered heterogeneity. In the vertical direction, the sediments were set as alternating beds of sand and clay with different permeabilities, and in the horizontal direction, the conditions are consistent (Figure 3). Then, a relatively ideal layered reservoir model was established to preliminarily discuss the formation of hydrate in the layered formation.

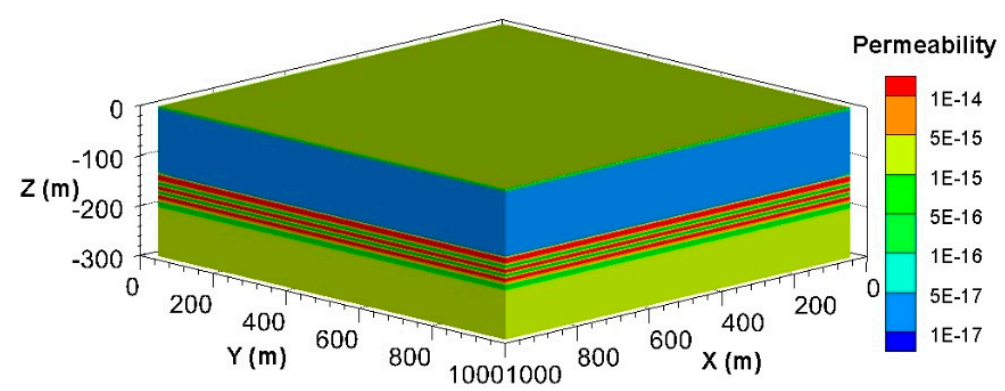

Figure 3. Permeability distribution of the layered heterogeneity model.

The distribution of gas and hydrate in the layered heterogeneous model at different simulation times is shown in Figure 4. It can be found that reservoirs with interbedding structures also form horizontally distributed hydrate layers like homogeneous models. However, the blocking effect of high and low permeability alternating layers on gas is larger than that of the homogeneous model, and the hydrate saturation is lower than the value of the homogeneous model at the same simulation time. Meanwhile, due to the blocked vertical gas supply, the thickness of the hydrate reservoir in this 
kind of sediment is smaller than that of homogeneous sediments. In the vertical passage of gas and sediments close to the passage, the gas migration is mainly convective and the flow velocity is relatively high, and the distribution difference of gas and hydrate between alternating layers is relatively small. At the front of gas migration, the lateral velocity of gas tends to zero, and the gas mainly migrates through diffusion. The gas migration in the high permeability layers is more significant than that in the low permeability layers, and the gas saturation is relatively higher. At the same time, the lateral gas migration in the high permeability layers is faster and further, which increases the lateral distribution range of hydrate. Thus, the hydrate deposits in the layered heterogeneous sediments present an obvious stratification phenomenon.

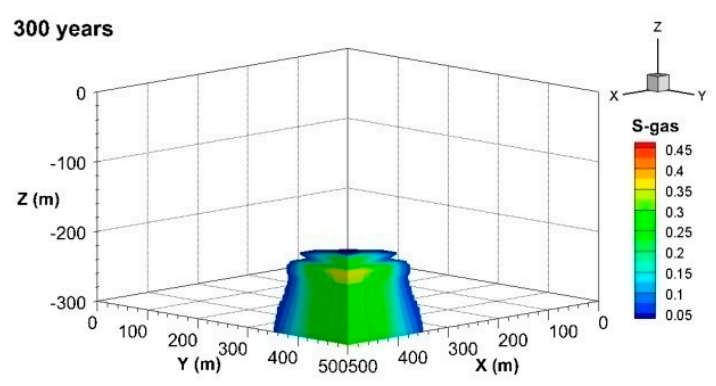

(a) Gas saturation

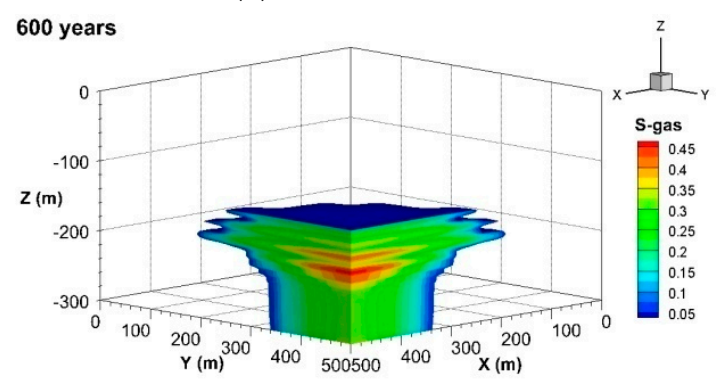

(c) Gas saturation

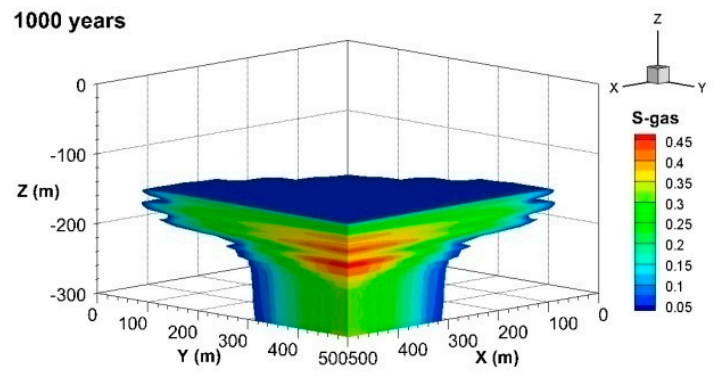

(e) Gas saturation

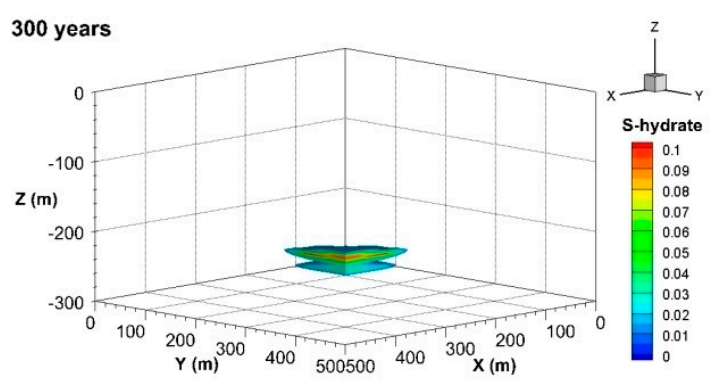

(b) Hydrate saturation

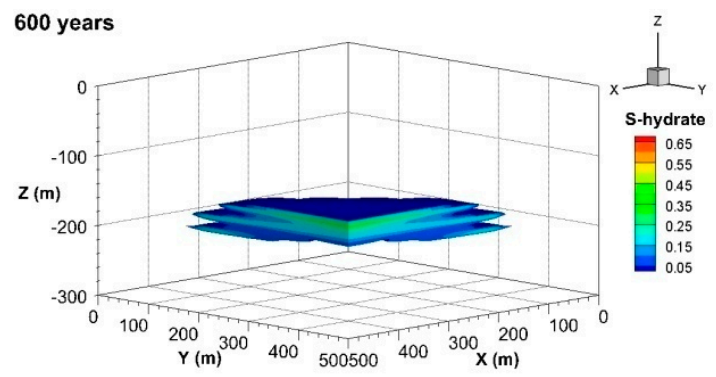

(d) Hydrate saturation

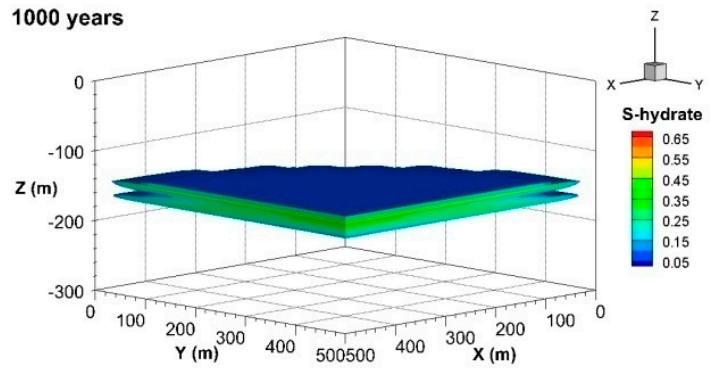

(f) Hydrate saturation

Figure 4. Gas and hydrate distribution at different simulated times (Case 1).

\subsection{Spatial Heterogeneity of the Reservoir}

Figure 5 shows the permeability distribution of a hydrate reservoir area with 137.95-191.5 m depth after random heterogeneity using Hetero-3d software. Relative areas of high and low permeability are also depicted separately to roughly show the internal permeability distribution. It can be found that the permeability has different distributions and combinations in both the horizontal x-direction and y-direction and the vertical z-direction. Therefore, the spatial heterogeneity model can be used to analyze the influence of spatial heterogeneity of porosity and permeability on hydrate formation and accumulation. 


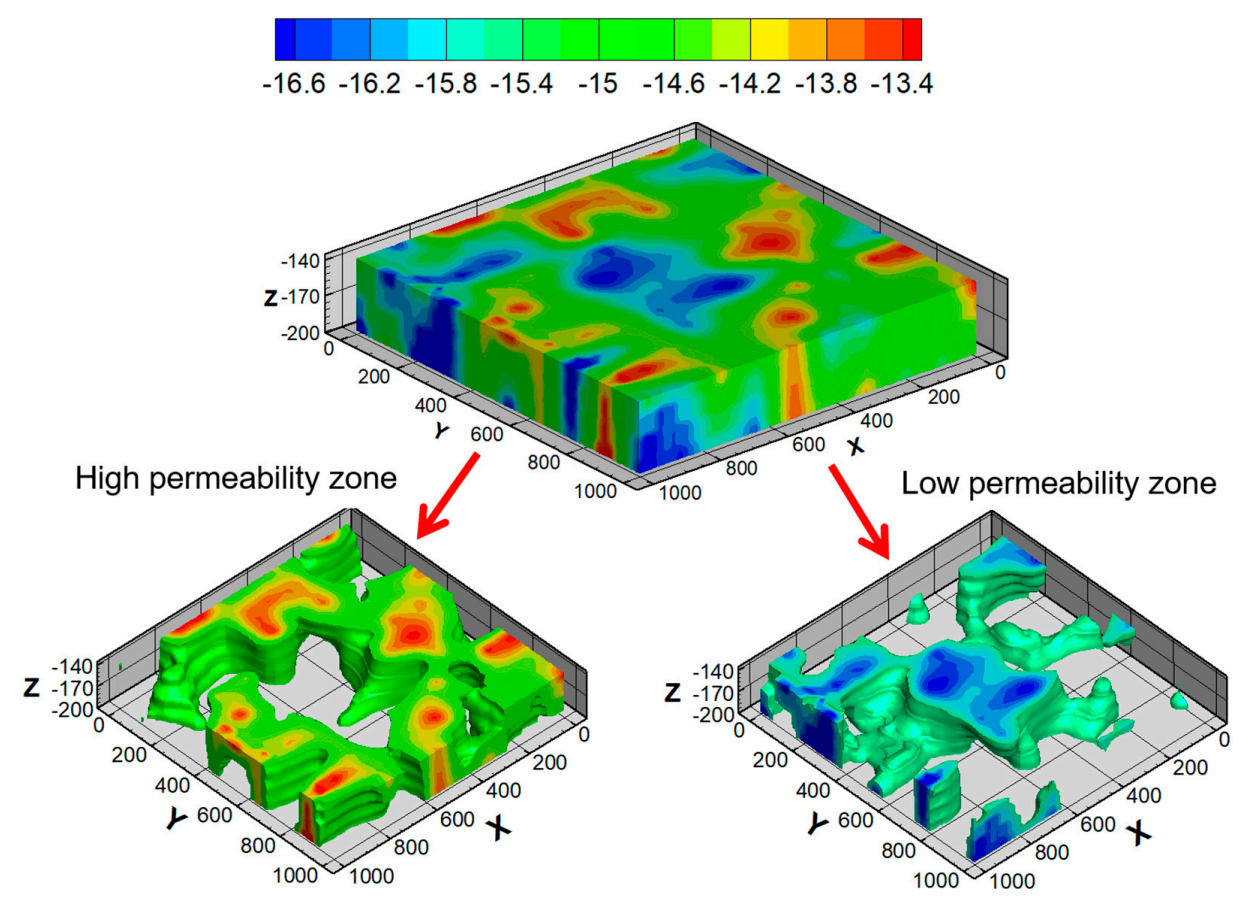

Figure 5. Permeability distribution of a hydrate reservoir with spatial heterogeneity.

Figure 6 shows the gas and hydrate distribution characteristics of spatially heterogeneous reservoirs with a simulation time of 1000 years. Figure $6 a, c$ show the gas and hydrate saturation on the section of $x, y=500 \mathrm{~m}$, respectively. Figure $6 \mathrm{~b}, \mathrm{~d}$ show the spatial distribution of gas and hydrate in reservoirs. The simulation results show that the direction of gas migration changes when the leakage gas enters the hydrate stability zone with heterogeneous porous space. Because of the gravity and methane buoyancy, there must be a difference between the contributions of lateral and vertical heterogeneity. Some of the gas is affected by the plugging effect of the low permeability sediments, and the migration velocity decreases and gradually accumulates in the lower part of the low permeability region. In the model, due to the random setting of heterogeneity, the spatial combinations of permeability are also diverse. These combinations can form some special structures, including some covers formed by low permeability grids and some channels formed by high permeability grids. Some gases continue to migrate along relatively high permeability channels, and the direction of migration is related to the distribution of high permeability channels. In this model, the gas migrates obliquely upward along the $\mathrm{X}$ direction (with an angle of about 30 degrees in the horizontal direction). The gas migrates obliquely upward in the reservoir until it encounters the overlying low permeability caprock, and then transfers horizontally. The gas saturation presents a non-uniform distribution in the reservoir as a whole. The formation of hydrate is closely related to the distribution of gas migration. The gases blocked by low permeability reservoirs migrate outward, mainly by diffusion, to form low saturation and deep buried hydrates. Some gas migrating upward along the high permeability channel forms inclined hydrates when it moves in the channel, and the other part of the gas forms hydrates in the process of lateral migration after encountering the overlying layer, which mainly distributes horizontally. The thickness of the hydrate layer is related to its distance from the vertical channel: the thicker the hydrate layer extends outwards, the smaller the thickness of the hydrate layer. In spatially heterogeneous reservoirs, hydrate saturation, burial depth and the thickness of the hydrate layer are not only controlled by the temperature and pressure conditions of the sedimentary layer, but also related to the distribution of reservoir porosity and permeability. The heterogeneity of the reservoir space directly affects the gas migration in the stable zone, and at the same time, it may form a local gas trap structure, controlling the formation and enrichment position of hydrate, which has a great influence on the formation and accumulation of marine hydrate. 


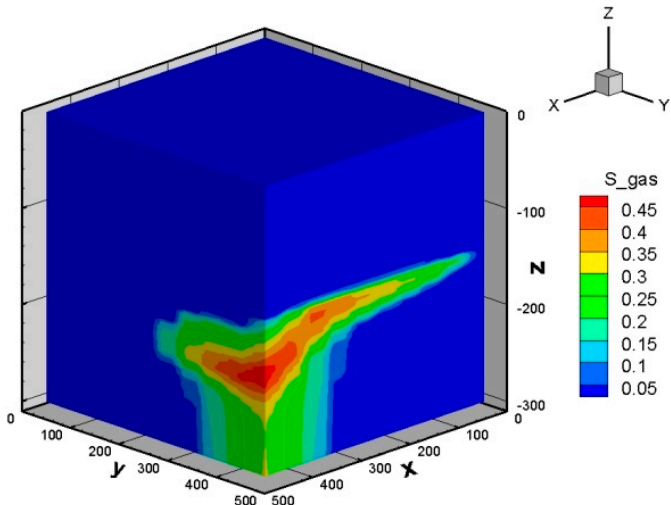

(a) Gas saturation ( $\mathrm{x}, \mathrm{y}=500 \mathrm{~m}$ section)

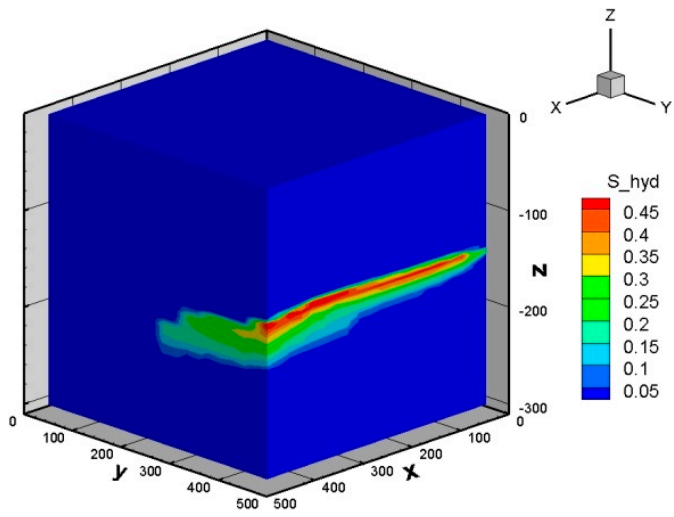

(c) hydrate saturation $(\mathrm{x}, \mathrm{y}=500 \mathrm{~m}$ section)

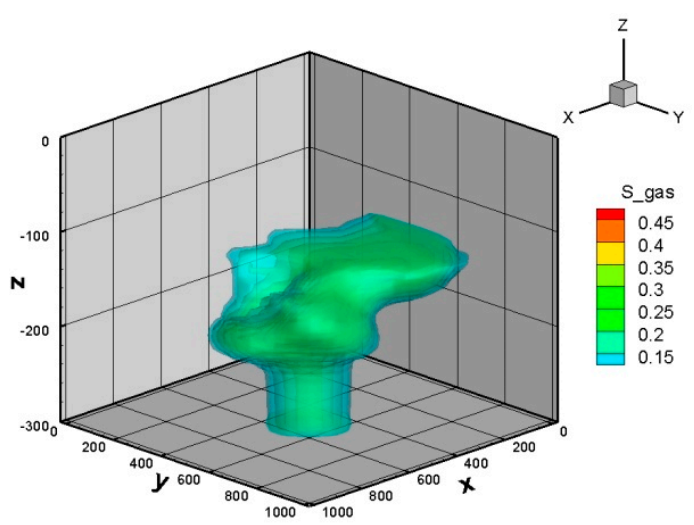

(b) Spatial gas distribution

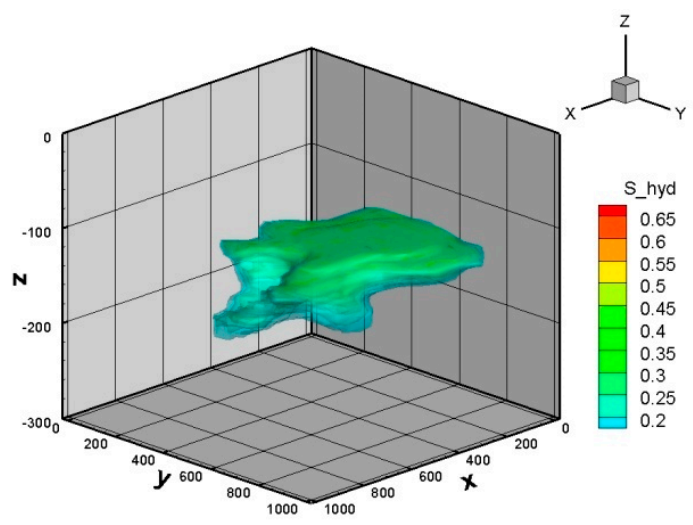

(d) Spatial hydrate distribution

Figure 6. Gas and hydrate distribution at a simulated time of 1000 years (Case 2).

In order to further explore the influence of spatial heterogeneity on gas migration and hydrate formation, based on the original model, the scheme of gas injection was changed from the middle pathway to the whole bottom surface. Figure 7 shows the simulated gas, hydrate and salinity distribution. The results of the surface injection model can more clearly show the important influence of heterogeneous marine formation on the migration and accumulation of lower leaking gas. Sediments with different permeabilities in their formation were combined vertically and horizontally in a variety of arrangements, which formed an advantageous channel or barrier for gas migration. Hydrate distribution also shows horizontal and vertical differential distribution under this condition.

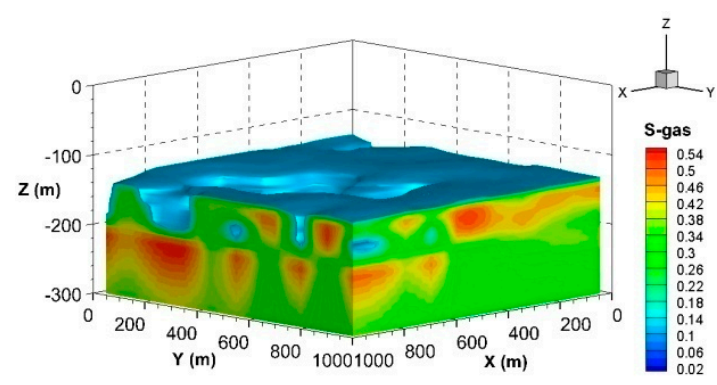

(a) gas saturation

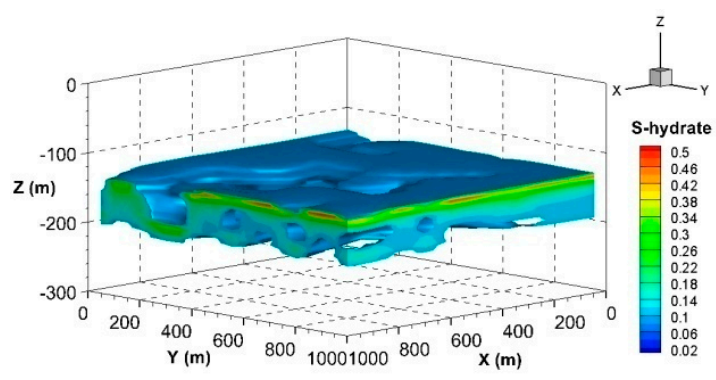

(b) hydrate distribution

Figure 7. Cont. 


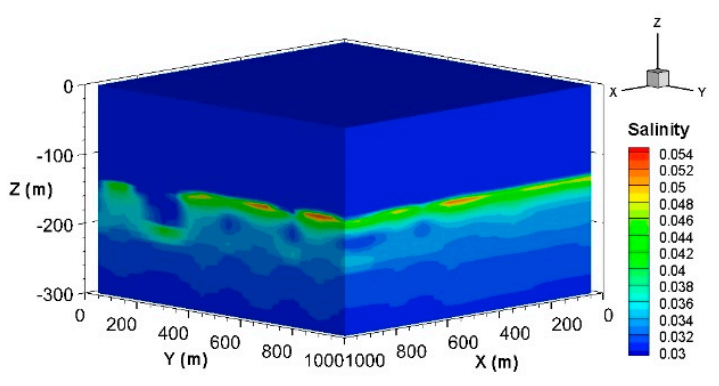

(c) salinity distribution

Figure 7. Gas, hydrate and salinity distribution at a simulated time of 1000 years (gas injection from the whole bottom surface).

\section{Discussion}

In marine sediments, the formation of hydrate is mainly affected by stable temperature and pressure conditions, the gas source, gas migration system and hydrate storage conditions. Reservoir heterogeneity has little influence on the gas source and stable hydrate conditions. In this study, we mainly discuss the influence of heterogeneous sediments on the formation and accumulation of gas hydrates from two aspects: hydrate storage conditions and gas migration conditions.

\subsection{Effect of Heterogeneous Sediments on Hydrate Storage Conditions}

In unconsolidated, fine-grained sediments since the late Miocene, gas hydrates are generally dispersed, lenticular, nodular, granular or sheet-like, while in coarse-grained sediments, gas hydrates are mostly porous or cemented. Generally, the higher the porosity of a porous medium, the smaller the capillary pressure corresponding to the pore, and the easier the gas intrudes into the pore water. This promotes the formation of hydrate in porous media, so that hydrate can migrate and accumulate in a higher saturation. In heterogeneous reservoirs, different porosity regions correspond to different reservoir space conditions. The higher the porosity, the more ideal the reservoir conditions are.

In the simulator employed in this paper, the salinity is used to calculate the equilibrium pressure and temperature of hydrate in each time step of simulation, and the corresponding change in salinity due to hydrate formation is also calculated at each time step. The distribution and saturation of the hydrate in the simulation results show the salinity effect to some extent. The regions with higher hydrate saturation (Figure $7 \mathrm{~b}$ ) correspondingly showed higher salinity (Figure 7c), and due to the inhibition of high salinity, the peak hydrate saturation no longer increased despite the sufficient supply of methane gas (Figure 7a). The formation process of hydrate is actually a process of three-phase equilibrium of hydrate-water solution-gas. The phase equilibrium curve of hydrate is correlated with the salinity of the water solution. Water salinity can inhibit hydrate formation; the higher the salinity, the more difficult hydrate formation is, and the lower the temperature and higher pressure required (Figure 8). The formation of hydrate consumes some of the water. Salinization increases the salinity of pore water near the area where hydrate is formed and changes the phase equilibrium curve. In heterogeneous reservoirs, if there is a high permeability channel in the hydrate formation area, the convection and diffusion rate of high concentration ions outward is faster, the salinity increase is not obvious, and the inhibition effect of salinity on hydrate formation is relatively weak. If the sediments near the hydrate deposits are composed of low permeability and weak circulation sediments, the effect of salinity increase is slower to alleviate, and a high salinity area easily appears locally. The hydrate further aggregates and eventually forms in a spatially inhomogeneous distribution of hydrate. This effect is more significant when the flux of the bottom seepage fluid is larger and the gas proportion in the fluid is higher. 

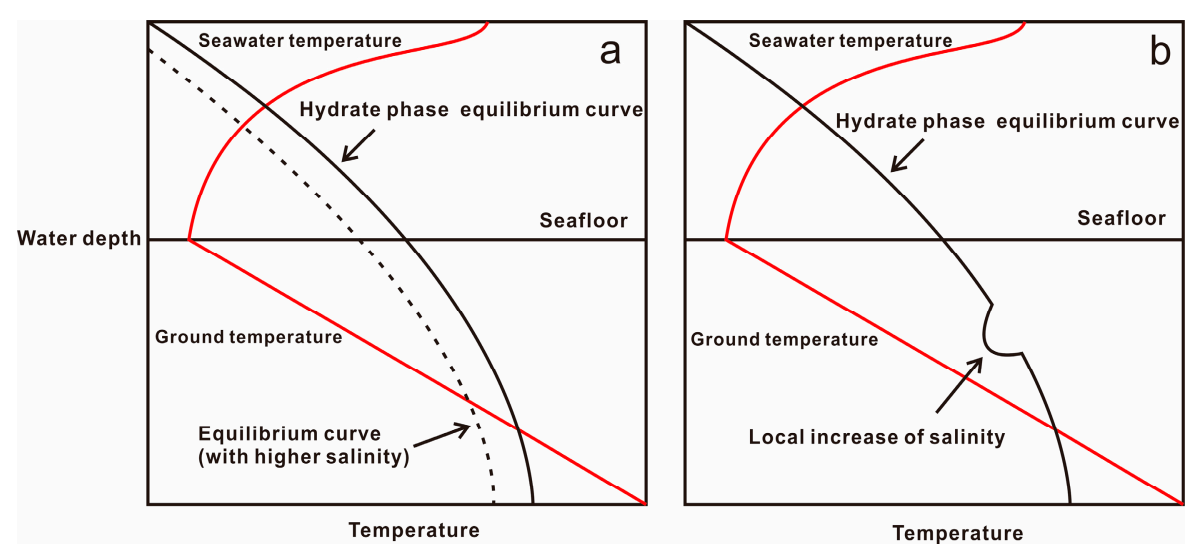

Figure 8. Effect of salinity on the phase equilibrium of hydrate. (a): change of equilibrium curve with higher salinity; (b): potential influence of local increase of salinity).

\subsection{Effect of Heterogeneous Sediments on Gas Migration}

Methane migrates in seabed sediments mainly in three ways: (1) diffusion; (2) fluid flux with methane dissolved in water, diffusion or convection in the liquid phase; and (3) gas phase migration under buoyancy [30]. The rate of gas migration by diffusion is very slow, and if there is a high flux gas leakage, the amount of gas diffusion and the low hydrate saturation formed by it can be neglected. When the gas flux moving upward in the underlying layer is large, the total methane content below the bottom of the hydrate stability zone exceeds the methane solubility, and a free gas layer will be formed below the bottom of the stable zone, which then migrates to the hydrate stability zone. The bottom boundary and thickness of the hydrate stability zone can be calculated theoretically. In principle, hydrate can be formed at all depths of the stable zone, but in fact, hydrate deposits in the hydrate stability zone are not continuous. Despite the possible depletion of methane by sulfate reduction in the upper part of shallow sediments, the discontinuity in the middle and lower part of the deposit is mainly controlled by the gas migration conditions, which is closely related to the permeability distribution of the sediments.

In the hydrate stability zone, hydrate formation occurs only when the total methane content is higher than the methane solubility. Figure 9 shows the hydrate formation mechanism under three typical gas migration conditions: (1) There is no low permeability plugging layer in the vertical homogeneous formation, and the high flux of lower gas corresponds to the high saturation and thick hydrate layer (Figure 9a); (2) If there is a low permeability plugging layer in the middle and upper part of the stable zone, when methane migrates to the low permeability layer, vertical migration weakens and lateral migration strengthens. The hydrate formed in this area is mainly located at the lower part of the stable zone, and the horizontal extension range is larger but the thickness is relatively smaller. This phenomenon also occurs when the hydrate layer has an obvious self-sealing effect (Figure 9b); (3) If there is a low permeability plugging layer at the lower part of the stable zone, only a small amount of methane enters the stable zone from the free zone, whereas when there is a lateral hypertonic gas transport channel, then a lateral gas supply will occur. When it exceeds the methane solubility, a hydrate layer will be formed in the channel or at the outlet of the channel. The location and depth of the hydrate are related to the channel (Figure 9c). In sediments with heterogeneous porosity and permeability, the gas migration processes are complex and diverse, and the hydrate formation mechanism is mostly the combination of the above three processes. 


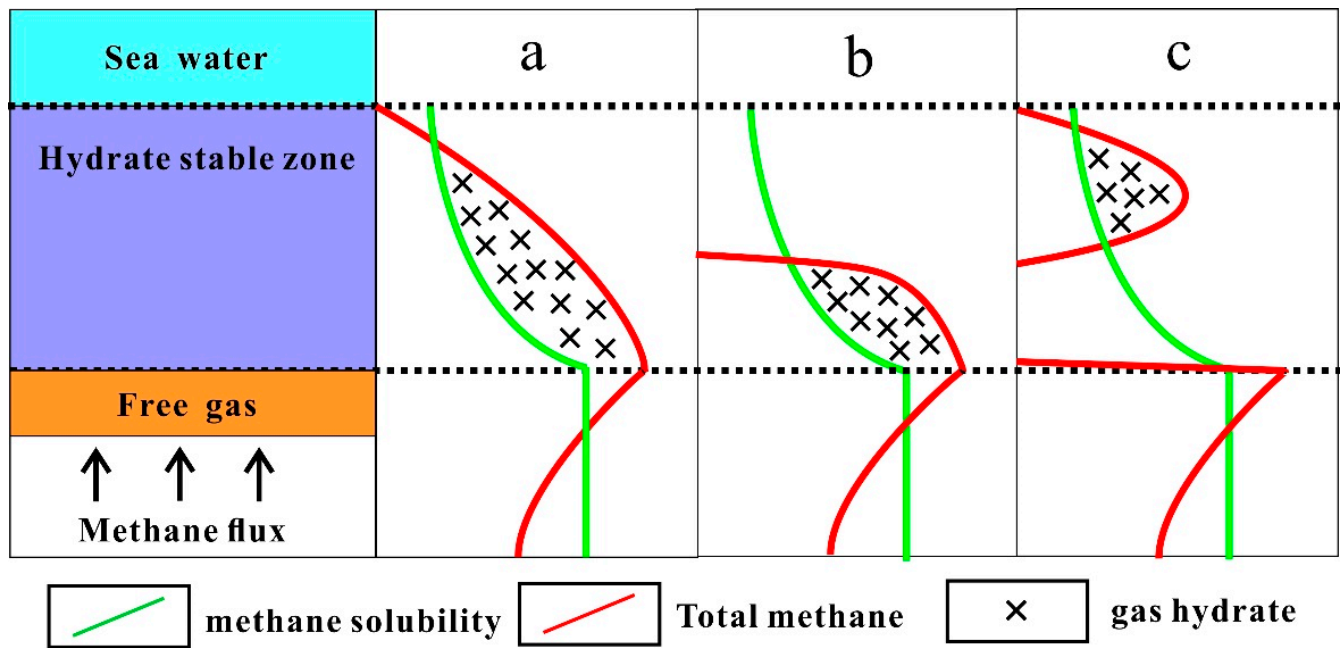

Figure 9. Hydrate formation mechanism under different gas migration conditions (with a high methane flux from the bottom).

\subsection{Comparison with Field Observations}

All the simulations carried out in this study are on large time scales, and the results usually cannot be verified with experiment data. Some field observations in terms of gas migration and hydrate formation in heterogeneous sediments are available in the previous literature. Comparisons between field observations and modeled results are detailed below.

According to the studies of $[29,30]$, the distribution of gas hydrate found in both voyages GMGS1 and GMGS3 showed strong lateral and vertical heterogeneity in the Shenhu area in the northern South China Sea. By summarizing and drawing comparisons, Wang et al. [30] found that high gas hydrate saturations correspond to high-density porosities at sites SH2, SH3, SH4, and SH7. Yang et al. [29] used a logging while drilling (LWD) borehole image log to study marine gas hydrates and found that the occurrence state and saturation of gas hydrates in the Shenhu area show an obvious stratification phenomenon. The hydrates with higher saturation and greater thickness are usually located at the top of the gas hydrate reservoir, whereas the gas hydrates with lower saturation are at the bottom. Marine gas hydrate explorations in the Eastern Nankai Trough of Japan also revealed a variable distribution of hydrate deposits with various conditions of permeability, porosity and hydrate saturation [45].

It is generally accepted that the occurrence of gas hydrate with high saturation is mostly controlled by the presence of coarse-grained sediments [46-48]. However, based on the comprehensive interpretation of cores, logging and 2D/3D seismic data of the Shenhu area, the gas hydrate in the Shenhu area was found mostly in fine-grained, clay-rich silts and silty sediments [49]. According to the studies of Chen et al. [50] and Wang et al. [30], the occurrence of calcareous fossils and foraminifers can increase the size and roundness of pores and provide more space for the nucleation and growth of gas hydrates in fine-grained sediments. It was also found that hydrates tend to occur in areas where the grain size of sediments is larger than that of the upper and lower boundaries [29] In this paper, we have not explored the reasons for the heterogeneity of porosity and permeability conditions, but these previous field studies showed consistent features (such as an obvious stratification phenomenon, high saturation located at the top of the reservoir, and hydrates tending to occur in areas with high permeability) with our simulation results. 


\section{Conclusions}

Through numerical simulations, the effects of heterogeneous porosity and permeability of sediments on the process of hydrate formation and accumulation in the stable region are studied and analyzed. The following conclusions are drawn:

(1) The heterogeneities in the porosity and permeability of the sedimentary layer in the hydrate stability region affect the local reservoir space conditions and the gas migration in the stable region, and consequently control the formation and accumulation position of hydrate.

(2) When the sediments in the hydrate reservoir show differences layer by layer, the gas that has migrated from the lower part of the reservoir is affected by the permeability of different layers, and layered differential gas migration characteristics appear, which makes the formation of hydrate saturation appear with a more obvious stratification phenomenon. At the same time, in the highly porous and permeable layers, the lateral gas supply range increases, which increases the horizontal distribution of hydrate deposits.

(3) The results of the spatial heterogeneity model show that when same methane leakage exists at the bottom, the hydrate saturation is different at different positions at the same depth, and some positions even have no hydrate formation. It was confirmed that the leakage of high flux methane or the existence of free gas layers (or BSRs) does not necessarily correspond to the occurrence of hydrates. There are also differences in the burial depth, saturation and distribution of hydrates under the same seepage conditions. When determining the formation/dominant area of hydrate in reservoirs, the spatial coupling relationship among conditions for hydrate stability, reservoir space and gas migration conditions should be comprehensively analyzed.

Author Contributions: Formal analysis, Z.W.; Software, S.S.; Writing-original draft, K.B.; Writing-review \& editing, T.X., Y.Y. and H.T.

Funding: This research was funded by "the National Key Research and Development Plan of China, grant number 2017YFC0307301", and partly supported by "the National Natural Science Foundation of China, grant number 41877185" and the National Natural Science Foundation of China, grant number 41772247".

Acknowledgments: The paper also benefited from Groundwater Resources and Environments Key Laboratory of Ministry of Education in Jilin University (China).

Conflicts of Interest: The authors declare no conflict of interest. The funders had no role in the design of the study; in the collection, analyses, or interpretation of data; in the writing of the manuscript, or in the decision to publish the results.

\section{References}

1. Milkov, A.V.; Sassen, R. Estimate of gas hydrate resource, northwestern Gulf of Mexico continental slope. Mar. Geol. 2001, 179, 71-83. [CrossRef]

2. Luff, R.; Wallmann, K. Fluid flow, methane fluxes, carbonate precipitation and biogeochemical turnover in gas hydrate-bearing sediments at Hydrate Ridge, Cascadia Margin: Numerical modeling and mass balances. Geochim. Cosmochim. Acta 2003, 67, 3403-3421. [CrossRef]

3. Zhang, G.; Huang, Y.; Zhu, Y.; Wu, B. Prospect of gas hydrate resources in the South China Sea. Mar. Geol. Quat. Geol. 2002, 22, 75-81.

4. Zhang, G.; Chen, F.; Sha, Z.; Liang, J.; Su, X.; Lu, H. The geological evolution process of natural gas hydrate reservoirs in the northeastern South China Sea. Earth Sci. Front. 2017, 24, 15-23.

5. Lin, C.; Lin, A.; Liu, C.; Chen, G.; Liao, Z.; Schnurle, P. Geological controls on BSR occurrences in the incipient arc-continent collision zone off southwest Taiwan. Mar. Pet. Geol. 2009, 26, 1118-1131. [CrossRef]

6. Su, P.; Liang, J.; Fu, S.; Lü, W.; Gong, Y. Geological background and accumulation models of gas hydrate reservoir in northern South China Sea. Geol. China 2017, 44, 415-427.

7. Davie, M.K.; Buffett, B.A. A numerical model for the formation of gas hydrate below the seafloor. J. Geophys. Res. Solid Earth 2001, 106, 497-514. [CrossRef]

8. Hu, G.; Li, C.; Ye, Y.; Liu, C.; Zhang, J.; Diao, S. Observation of gas hydrate distribution in sediment pore space. Chin. J. Geophys. 2014, 57, 1675-1682. 
9. Chen, Q.; Liu, C.; Xing, L.; Hu, G.; Meng, Q.; Sun, J.; Jin, X. Resistivity variation during hydrate formation in vertical in homogeneous distribution system of pore water. Acta Pet. Sin. 2016, 37, 222-229.

10. Li, C.; Hu, G.; Zhang, W.; Ye, Y.; Liu, C.; Li, Q.; Sun, J. Influence of foraminifera on formation and occurrence characteristics of natural gas hydrates in fine-grained sediments from Shenhu area, South China Sea. Sci. China Earth Sci. 2016, 59, 2223-2230. [CrossRef]

11. Grevemeyer, I.; Villinger, H. Gas hydrate stability and the assessment of heat flow through continental margins. Geophys. J. Int. 2001, 145, 647-660. [CrossRef]

12. Liang, J.; Wang, H.; Su, X.; Fu, S.; Wang, L.; Guo, Y.; Chen, F.; Shang, J. Natural gas hydrate formation conditions and the associated controlling factors in the northern slope of the South China Sea. Nat. Gas Ind. 2014, 34, 128-135.

13. Su, Z.; Cao, Y.; Yang, R.; Wu, N.; Yang, S.; Wang, H. Analytical research on evolution of methane hydrate deposits at Shenhu Area, northern South China Sea. Chin. J. Geophys. 2012, 55, 1764-1774.

14. Su, M.; Sha, Z.; Zhang, C.; Wang, H.; Wu, N.; Yang, R.; Liang, J.; Qiao, S.; Cong, X.; Liu, J. Types, Characteristics and Significances of Migrating Pathways of Gas-bearing Fluids in the Shenhu Area, Northern Continental Slope of the South China Sea. Acta Geol. Sin. Engl. Ed. 2017, 91, 219-231. [CrossRef]

15. Guo, Y.; Yang, S.; Liang, J.; Lu, J.; Lin, L.; Kuang, Z. Characteristics of high gas hydrate distribution in the Shenhu Area on the northern slope of the South China Sea. Earth Sci. Front. 2017, 24, 24-31.

16. Yang, S.; Liang, J.; Lu, J.; Qu, C.; Liu, B. New understandings on the characteristics and controlling factors of gas hydrate reservoirs in the Shenhu area on the northern slope of the South China Sea. Earth Sci. Front. 2017, 24, 1-14.

17. Wang, J.; Liang, J.; Zong, X.; Gong, Y.; Wan, T. Differentiated distribution of methane hydrate in the Shenhu Area of the northern South China Sea and controlling factors. Mar. Geol. Front. 2015, 31, 24-30.

18. Zhang, H.; Lu, H.; Liang, J.; Wu, N. The methane hydrate accumulation controlled compellingly by sediment grain at Shenhu, northern South China Sea. Chin. Sci. Bull. 2016, 61, 388-397. [CrossRef]

19. Malinverno, A. Marine gas hydrates in thin sand layers that soak up microbial methane. Earth Planet. Sci. Lett. 2010, 292, 399-408. [CrossRef]

20. Chatterjee, S.; Bhatnagar, G.; Dugan, B.; Dickens, G.; Chapman, W.; Hirasaki, G. The impact of lithologic heterogeneity and focused fluid flow upon gas hydrate distribution in marine sediments. J. Geophys. Res. Solid Earth 2014, 119, 6705-6732. [CrossRef]

21. Nole, M.; Daigle, H.; Cook, A.E.; Malinverno, A. Short-range, overpressure-driven methane migration in coarse-grained gas hydrate reservoirs. Geophys. Res. Lett. 2016, 43, 9500-9508. [CrossRef]

22. Li, S.; Chu, F.; Fang, Y.; Wu, Z. Associated interpretation of sub-bottom and single-channel seismic profiles from slope of Shenhu Area in the northern South China Sea-Characteristics of gas hydrate sediment. J. Trop. Oceanogr. 2010, 29, 56-62.

23. He, L.; Lei, X.; Zhang, Y. Numerical modeling of gas hydrate accumulation in the marine sediments of Shenhu area, northern South China Sea. Chin. J. Geophys. 2011, 54, 299-306. [CrossRef]

24. Zhang, Y.; He, L.; Wang, J.; Xu, X.; Sha, Z.; Gong, Y.; Wang, H.; Liang, J. Heat flow pattern, base of methane hydrates stability zones and BSRs in Shenhu Area, northern South China Sea. Acta Oceanol. Sin. 2011, 30, 59-67. [CrossRef]

25. Wu, N.; Zhang, H.; Yang, S.; Liang, J.; Wang, H.; Su, X.; Lu, Z.; Fu, S.; Zhang, G.; Lu, J. Preliminary discussion on natural gas hydrate (NGH) reservoir system of Shenhu Area, north slope of South China Sea. Nat. Gas Ind. 2007, 27, 1-6.

26. He, J.; Yan, W.; Zhu, Y.; Zhang, W.; Gong, F.; Zhang, S.; Zhang, J.; Gong, X. Bio-genetic and sub-biogenetic gas resource potential and genetic types of natural gas hydrates in the northern marginal basins of South China Sea. Nat. Gas Ind. 2013, 33, 121-134.

27. Zhu, Q.; Wu, Q.; Wu, X.; He, L.; Hou, Z. A comparative study on gas hydrate accumulations in Shenhu area and Xisha trough. Marine Geol. Front. 2017, 33, 55-62.

28. Wang, J.; Wu, S.; Kong, X.; Li, Q.; Wang, J.; Ding, R. Geophysical characterization of a fine-grained gas hydrate reservoir in the Shenhu area, northern South China Sea: Integration of seismic data and downhole logs. Mar. Pet. Geol. 2018, 92, 895-903. [CrossRef]

29. Yang, S.; Zhang, M.; Liang, J.; Lu, J.; Lu, J.; Zhang, Z.; Melanie, H.; Peter, S.; Fu, S.; Sha, Z. Preliminary results of China's Third Gas Hydrate Drilling Expedition: A critical step from discovery to development in the South China Sea: Fire in the Ice. Cent. Nat. Gas Oil 2015, 412, 386-7614. 
30. Wang, X.; Collett, T.; Lee, M.; Yang, S.; Guo, Y.; Wu, S. Geological controls on the occurrence of gas hydrate from core, downhole log, and seismic data in the Shenhu area, South China Sea. Mar. Geol. 2014, 357, 272-292. [CrossRef]

31. Moridis, G.J.; Reagan, M.T. Estimating the upper limit of gas production from Class 2 hydrate accumulations in the permafrost: 2. Alternative well designs and sensitivity analysis. J. Pet. Sci. Eng. 2011, 76, $124-137$. [CrossRef]

32. Moridis, G.J. User's Manual for the Hydrate v1. 5 Option of TOUGH+ v1. 5: A Code for the Simulation of System Behavior in Hydrate-Bearing Geologic Media. Available online: https://www.osti.gov/servlets/purl/ 1165986 (accessed on 1 November 2014).

33. Jin, G.; Xu, T.; Xin, X.; Wei, M.; Liu, C. Numerical evaluation of the methane production from unconfined gas hydrate-bearing sediment by thermal stimulation and depressurization in Shenhu area, South China Sea. J. Nat. Gas Sci. Eng. 2016, 33, 497-508. [CrossRef]

34. Sun, J.; Zhang, L.; Ning, F.; Lei, H.; Liu, T.; Hu, G.; Lu, H.; Lu, J.; Liu, C.; Jiang, G.; et al. Production potential and stability of hydrate-bearing sediments at the site GMGS3-W19 in the South China Sea: A preliminary feasibility study. Mar. Pet. Geol. 2017, 86, 447-473. [CrossRef]

35. Wan, Y.; Wu, N.; Hu, G.; Xin, X.; Guang, R.; Liu, C.; Chen, Q. Reservoir stability in the process of natural gas hydrate production by depressurization in the Shenhu area of the South China Sea. Nat. Gas Ind. 2018, 4, 117-128. [CrossRef]

36. Rutqvist, J.; Moridis, G.J. Numerical Studies on the Geomechanical Stability of Hydrate-Bearing Sediments. SPE J. 2009, 14, 267-282. [CrossRef]

37. Van Genuchten, M.T. A closed-form equation for predicting the hydraulic conductivity of unsaturated soils 1. Soil Sci. Soc. Am. J. 1980, 44, 892-898. [CrossRef]

38. Moridis, G.J.; Seol, Y.; Kneafsey, T.J. Studies of Reaction Kinetics of Methane Hydrate Dissocation in Porous Media. In Proceedings of the Fifth International Conference on Gas Hydrates, Berkeley, CA, USA, 10 March 2005; pp. 21-30.

39. Moridis, G.J. TOUGH+ HYDRATE v1. 2 User's Manual: A Code for the Simulation of System Behavior in Hydrate-Bearing Geologic Media. Available online: https://www.osti.gov/servlets/purl/1173164 (accessed on 4 April 2014).

40. Zhang, K.; Moridis, G.; Wu, N.; Li, X.; Reagan, M. Evaluation of alternative horizontal well designs for gas production from hydrate deposits in the Shenhu Area, South China Sea. In Proceedings of the International Oil and Gas Conference and Exhibition in China, Society of Petroleum Engineers, Beijing, China, 8-10 June 2010.

41. Yuan, Y.; Xu, T.; Xin, X.; Xia, Y. Multiphase Flow Behavior of Layered Methane Hydrate Reservoir Induced by Gas Production. Geofluids. 2017, 2017. [CrossRef]

42. Zhu, H.; Xu, T.; Feng, G.; Yuan, Y.; Jiang, Z. Numerical modeling of the performance of the CO2-plume geothermal system in a permeability and porosity heterogeneous reservoir. Acta Energ. Sol. Sin. 2017, 38, 1814-1821.

43. Nelson, P.H. Permeability-Porosity Relationships in Sedimentary Rocks; The log analyst; Society of Petrophysicists and Well-Log Analysts: Houston, TX, USA, 1994; p. 35.

44. Tian, H.L.; Pan, F.; Xu, T.F.; McPherson, B.J.; Yue, G.F.; Mandalaparty, P. Impacts of hydrological heterogeneities on caprock mineral alteration and containment of $\mathrm{CO} 2$ in geological storage sites. Int. J. Greenh. Gas Control 2014, 24, 30-42. [CrossRef]

45. Fujii, T.; Suzuki, K.; Takayama, T.; Tamaki, M.; Komatsu, Y.; Konno, Y.; Yoneda, J.; Yamamoto, K.; Nagao, J. Geological setting and characterization of a methane hydrate reservoir distributed at the first offshore production test site on the Daini-Atsumi Knoll in the eastern Nankai Trough, Japan. Mar. Pet. Geol. 2015, 66, 310-322. [CrossRef]

46. Cook, A.E.; Goldberg, D. Extent of gas hydrate filled fracture planes: Implications for in situ methanogenesis and resource potential. Geophys. Res. Lett. 2008, 35, 1-5. [CrossRef]

47. Lee, M.W.; Collett, T.S. Gas hydrate saturations estimated from fractured reservoir at Site NGHP-01-10, Krishna-Godavari Basin, India. J. Geophys. Res. Solid Earth 2009. [CrossRef]

48. Kim, G.; Narantsetseg, B.; Ryu, B.; Yoo, D.; Lee, J.; Kim, H.; Riedel, M. Fracture orientation and induced anisotropy of gas hydrate-bearing sediments in seismic chimney-like-structures of the Ulleung Basin, East Sea. Mar. Pet. Geol. 2013, 47, 182-194. [CrossRef] 
49. Chen, F.; Su, X.; Zhou, Y.; Lu, H.; Liu, G.; Chen, Z.; Chen, C. Variations in biogenic components of late Miocene-Holocene sediments from Shenhu area in the northern South China Sea and their geological implication. Mar. Geol. Quat. Geol. 2009, 29, 1-8.

50. Zhang, W.; Liang, J.; Lu, J.; Yu, J.; Su, P.; Fang, Y.; Guo, Y.; Yang, S.; Zhang, G. Accumulation features and mechanisms of high saturation natural gas hydrate in Shenhu Area, northern South China Sea. Pet. Explor. Dev. 2017, 44, 708-719. [CrossRef]

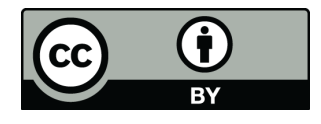

(C) 2019 by the authors. Licensee MDPI, Basel, Switzerland. This article is an open access article distributed under the terms and conditions of the Creative Commons Attribution (CC BY) license (http://creativecommons.org/licenses/by/4.0/). 